\title{
Measuring Building Height Using Point Cloud Data Derived from Unmanned Aerial System Imagery in an Undergraduate Geospatial Science Course
}

\author{
David Kulhavy ${ }^{1}$, I-Kuai Hung ${ }^{1}$, Daniel R. Unger ${ }^{1}$, Reid Viegut ${ }^{1} \&$ Yanli Zhang ${ }^{1}$ \\ ${ }^{1}$ Arthur Temple College of Forestry and Agriculture, Stephen F. Austin State University, Nacogdoches, Texas, \\ USA \\ Correspondence: David L. Kulhavy, Arthur Temple College of Forestry and Agriculture, Stephen F. Austin State \\ University, Nacogdoches, Texas, USA. Tel: 1-936-468-3301. E-mail: dkulhavy @ sfasu.edu
}

Received: November 16, 2020

Accepted: December 23, 2020 Online Published: January 5, 2020

doi:10.5539/hes.v11n1p105

URL: https://doi.org/10.5539/hes.v11n1p105

\begin{abstract}
The use of Unmanned Aerial Systems (UAS), also known as drones is increasing in geospatial science curricula within the United States. Within the Arthur Temple College of Forestry and Agriculture (ATCOFA) at Stephen F. Austin State University, Texas, seniors in the geospatial science program complete capstone projects to evaluate current geospatial technology to investigate complex ecological, social and environmental issues. Under the umbrella of a student initiated and designed senior project, students designed a study to estimate height of buildings with UAS data incorporating UAS data, LP360 and ArcScene programs, and Pictometry web-based interface. Results from a statistical analysis of the data confirm that geospatial science height estimation techniques can provide accurate estimates of height remotely. The independence of the students completing the project with UAS data for LP360 and ArcScene estimations, and utilizing Pictometry as an on-onscreen measuring tool, point to the need to integrate remote sensing, statistical analysis and synthesis of data into undergraduate geospatial science curricula. This reinforces the hands-on learning approach within ATCOFA and provides guidance to integrate the use of UAS in natural resource education.
\end{abstract}

Keywords: height estimation, student project, curricula, UAS

\section{Introduction}

\subsection{Accurate Height Measurements}

The use of Unmanned Aerial Systems (UAS) (also known as drones) is increasing in geospatial science curricula for teaching, research and service. Within the Arthur Temple College of Forestry and Agriculture (ATCOFA) at Stephen F. Austin State University, seniors in the geospatial science curriculum are required to complete a capstone project to use the most current technology to investigate complex ecological, social and environmental issues to create a viable product (Bullard et al., 2014). Often UASs are used to complete projects and produce products across the natural resources and geospatial science curriculum. The use of a UAS to capture remotely sensed images at the user's discretion in natural resources add to the advantages in teaching and research (Unger, Kulhavy, Hung, Zhang \& Stephens Williams, 2019). Students are trained in the safe use of UAS by a team of four geospatial science faculty members including safe operation, flying the UAS for individual images, video and orthophoto missions using a four-step training process of UAS assembly, completing a controlled flight, capturing imagery and videos, and synthesizing UAS information to quantify and qualify natural resource missions (Unger, Kulhavy, Busch-Petersen \& Hung, 2016; Unger, Kulhavy, Hung, Zhang \& Stephens Williams, 2019). Once students are trained, they complete a self-designed project with the supervision of one of the faculty members involving collecting and processing data.

During the training process, geospatial science majors are introduced to service-learning that includes reflection on the importance of the remote sensing project in building a broader sense of civic responsibility (Bringle \& Hatcher, 1995, 2002), reinforcing the idea of working with partners to develop community relationships so each partner has a voice and an essential role (Warren-Gordon, Hudson \& Scott, 2020). Each student meets with geospatial science firms using UAS in their operations, and UAS companies that produce products using UAS. These representatives meet with the geospatial faculty to add input to their remote sensing projects. This 
information is added to coursework and the forestry curriculum as examples of the use of UAS in society (Unger, Kulhavy, Hung, Zhang \& Stephens Williams, 2019).

One project centered on the accuracy of building height measurements across a series of methods, including the use of UAS. Building height accuracy is essential for geospatial science, natural resources and city planning and can be obtained from a laser range finder or clinometer in the field, or remotely on a computer screen with programs such as Google Earth Pro or Pictometry hyperspatial imagery. However, the accuracy of these methods needs to be evaluated with each actual height measured with a measuring rod.

The accuracy of height estimates using a UAS, is an alternative depending on the internal GPS or/and internal barometer onboard a drone that is user controlled (Khanna et al., 2015; Themistocleous, 2014; Unger, Kulhavy, Busch-Petersen, \& Hung, 2016). For accuracy with height measurements, landing the UAS DJI Phantom 3 between each flight increased the accuracy of the measurement even with the GPS turned off (Unger, Hung, Kulhavy, Zhang, \& Busch-Petersen, 2018). For heights with the DJI Phantom 3, the onboard barometer chip is the main device for comparing ground level as zero and measurements above the ground. As the barometer heights degrade overtime, it is necessary to land the UAS and reset the system (Unger, Hung, Kulhavy, Zhang \& Busch-Petersen, 2018). UAS can be flown in pre-determined flight patterns and orthomosaics developed in 2D or 3D depending on the software (Kulhavy et al., 2017; Hung, Unger, Kulhavy \& Zhang, 2019). Aerial 3D building reconstruction with Pix4DCapture and Drone2Map software were used to create a building point cloud (WuDunn, Zakhor, Touzani, \& Granderson, 2020). WuDunn, Dunn, \& Zakhor (2020) used a semantic segmentation approach of 3D point clouds for a building reconstruction. Latha, NagaSundari, Cherukuei, \& Prasad (2019) found a $0.38 \mathrm{~m}$ difference for a $15 \mathrm{~m}$ high building using a UAS.

\subsection{Pictometry Data}

Pictometry is classified as hyperspatial resolution remotely sensed data with aerial images taken from four cardinal directions and nadir allowing for 3D visualization of Earth's surface features. Its subscription-based web interface comes with measuring tools for the user to take measurements of length, area, and height on objects identified on screen. Kulhavy, Unger, Hung \& Douglass (2015) estimated building heights comparing Pictometry, LiDAR and a laser range finder to measured building heights. Pictometry was not different from the laser range finder, but was different from the LiDAR. Unger, Hung \& Kulhavy (2014) assessed the accuracy of light poles measured with Pictometry and found 1.77 to $2.39 \%$ error of the actual height. Kulhavy, Unger, Zhang, Bedford and Hung (2016) found no difference in slope distance between Pictometry, total station and a tape measurement. Unger, Kulhavy Williams, Creech, \& Hung (2015) found a 0.99 linear correlation of baldcypress tree height measured with Pictometry measured height and actual tree height.

\subsection{Unmanned Aerial Systems (UAS)}

UAS can provide accurate information on natural resource management and add to the accreditation curriculum standards of the Society of American Foresters (SAF, 2016). One of the routines in UAS applications is to generate orthomosaic imagery of a study area. Each aerial image taken by a UAS in a grid pattern comes with its geographic coordinates. All of the images are processed together to produce a continuous coverage. Through geographic positioning, edge matching, and photogrammetry, this orthorectify process generates not only a mosaic image, but also a digital surface model, and a point cloud. This point cloud dataset can be viewed in a 3D viewer to identify 3D objects and take measurements. Viegut, Kulhavy, Unger, Hung \& Humphreys (2018) indicated Pictometry and Google Earth Pro were more accurate than a DJI Phantom 4 Pro UAS for areal and linear measurements. A DJI Phantom 4 Advanced UAS was integrated into undergraduate forestry instruction to enhance learning of remotely-sensed spatial information (Unger, Hung, Zhang \& Kulhavy, 2018). Kulhavy, Unger, Hung \& Zhang (2016) found no difference in visual assessment and UAS assessment of urban tree hazard rating. Twice as many mistletoe plants were counted using the DJI Phantom 4 Pro UAS compared to ground surveys (Kulhavy et al., 2019). UAS were integrated into service-learning for a capstone forestry course (Kulhavy et al., 2017). UAS use is increasing in teaching, research and service across the curriculum and they are an essential tool for natural-resource management decision-making (Unger, Kulhavy, Hung, Zhang \& Stephens Williams, 2019).

\subsection{LP360 and ArcScene}

LP360 is a LiDAR and point cloud processing software program for extracting information and deriving products from point clouds in a standalone or in an ArcGIS environment. Unlike LiDAR, the point cloud dataset derived from drone imagery does not have multiple returns. Those points are attained through photogrammetry during the process of orthomosaicking and structure from motion (SFM). It does not capture features in 3D as detailed as LiDAR point cloud due to UAS image resolution and computational capacity of desktop computers. 
However, when viewing the point cloud stored in the drone LAS file in a LP360 viewer, buildings can still be identified and measured for height. Another program used for viewing the same point cloud is ArcScene, which is part of ArcGIS Desktop. ArcScene allows for 3D visualization and editing. It can read a point cloud dataset in native LAS format, requiring no data conversion. The LAS Dataset toolset in ArcScene has tools for point cloud display by attributes, tools for filtering by classification, and tools for deriving output for slope, aspect, and contour. The Measure Height tool in the Measure toolset was used for measuring building heights when viewing the point cloud in 3D.

ArcScene can be used to create a 3D model (Gross and Kennelly, 2005). UAS can be flown in a programmed flight to capture aerial imagery and produce an orthomosaic through a digital image processing program, such as Drone2Map by ESRI, in a timely and cost effective procedure (Hung, Unger, Kulhavy, \& Zhang, 2019). Viewing the point cloud derived from UAS in LP360 and ArcScene, building height can be extracted and measured.

\section{Methods}

Within the geospatial science Landscape Modeling capstone course, a senior student designed a study to estimate building heights with products derived from a DJI Phantom 3 Advanced UAS imagery. Following the development of an orthomosaic of the Jim and Beth Kingham Children's Garden at Stephen F. Austin State University from aerial images taken at an altitude above ground of 380 feet with 80 percent endlap and 70 percent sidelap, a point cloud dataset in LAS format was also attained (Figure 1). The LAS dataset was viewed in both LP360 and ArcScene for building identification and height measurement.

To assess the accuracy on height measurement, a total of 30 buildings were selected. Each was identified in LP360 and ArcScene for height measurement. In addition, the same buildings were identified and measured in Pictometry, which has been proved with satisfactory accuracy in measuring height. Finally, each building was measured in situ using a height measuring rod to obtain actual height. By calculating the root mean square error (RMSE) for each remote measurement approach, the accuracy was assessed and compared between the three, LP360, ArcScene, and Pictometry. Furthermore, an analysis of variance (ANOVA) was conducted to determine if there is significant difference on the mean absolute error among the three height measurement methods.

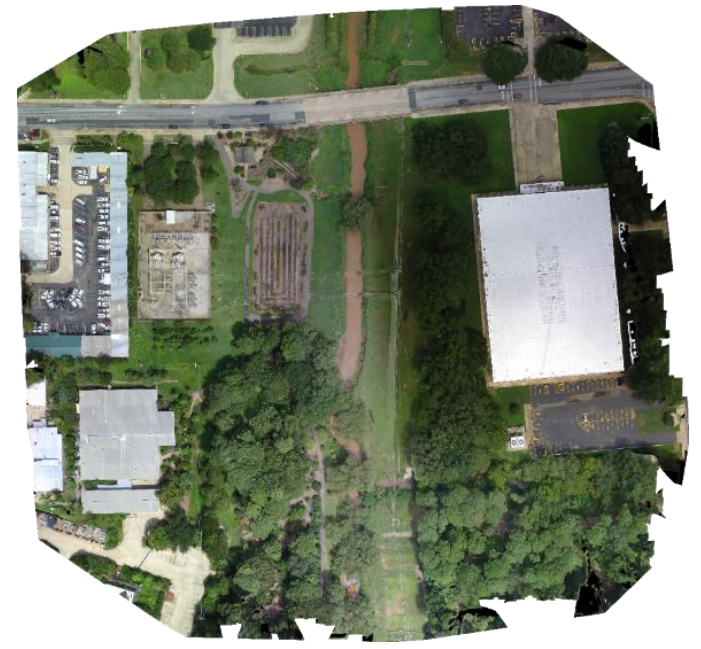

Figure 1. Drone derived orthophotomosaic of Jim and Beth Kingham Children's Garden

\section{Results}

A total of 30 buildings were selected for comparing the accuracy of height measurement. Each building was measured using the point cloud data collected by the drone viewed as a LAS dataset in LP360 and viewed in ArcScene, respectively. Then the same buildings were measured in the Pictometry web interface (Figure 2). The actual height of each building was also measured in the field using a height pole. Table 1 shows all of the building heights measured in meters. 

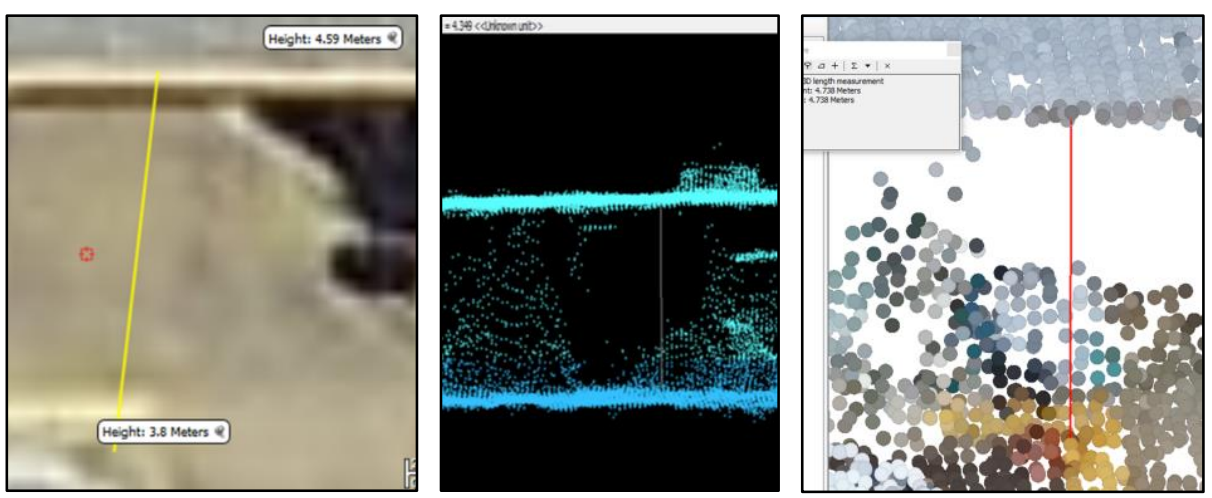

Figure 2. Building height measurement with Pictometry (left), LP360 (center) and ArcScene (right)

Measurement error was calculated by comparing an on-screen height measurement to each actual height of the building and summarized in Table 2. The distribution of height measurement errors is also displayed in Figure 3. It was found that the errors from Pictometry were more clustered with the lowest standard deviation $(0.0527 \mathrm{~m})$ compared to others. Errors from LP360 were the most spread out $(\mathrm{SD}=0.1585 \mathrm{~m})$ and showed an overall tendency of overestimating the height $($ mean $=0.1280 \mathrm{~m})$. For Pictometry, its lowest standard deviation and its mean of errors being closest to zero $(-0.0127 \mathrm{~m})$ indicates that Pictometry is the most accurate in height measurement comparing to others. This is also backed by the root mean square error (RMSE), where Pictometry achieved the lowest $(\mathrm{RMSE}=0.0534 \mathrm{~m})$, while LP360 is the worst with its RMSE of $0.2017 \mathrm{~m}$.

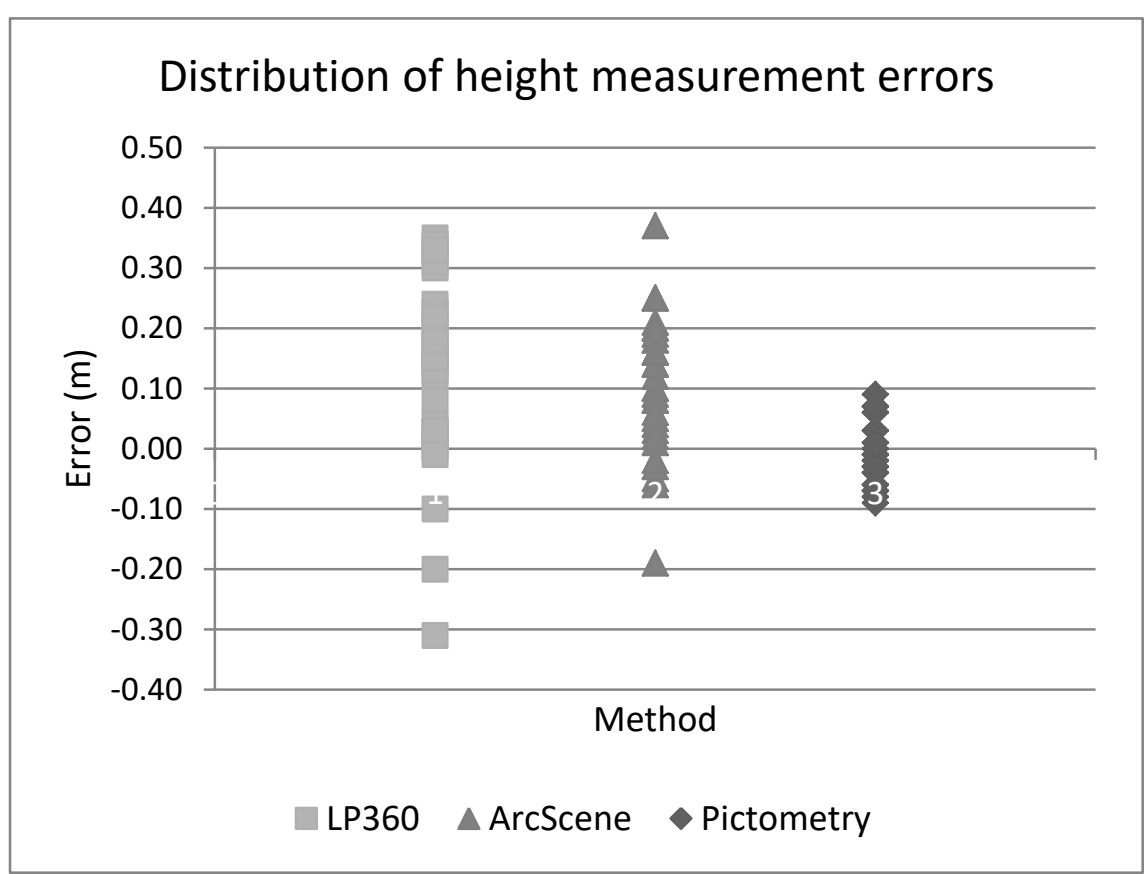

Figure 3. Distribution of height measurement errors by method used

To determine if there is any statistically significant difference on the accuracy of height measurement between the three methods, LP360, ArcScene, and Pictometry, an analysis of variance (ANOVA) was performed on the absolute errors of the height measurement at the significant level of 0.05 . The results are shown in Table 3 with the mean absolute error for Pictometry being the lowest at $0.0460 \mathrm{~m}$, followed by ArcScene $0.1247 \mathrm{~m}$, and then LP360 $0.1693 \mathrm{~m}$. The difference on the mean absolute error is significant with the p-value less than 0.0001 . A Tukey test followed and confirmed that the accuracy of Pictometry is significantly better than the others; whereas there is no significant difference between LP360 and ArcScene. 
Table 1. Measured building heights by method used (Unit: meter)

\begin{tabular}{lllll}
\hline Building & LP360 & ArcScene & Pictometry & Actual \\
\hline 1 & 8.97 & 8.82 & 8.65 & 8.64 \\
2 & 13.91 & 13.88 & 13.8 & 13.87 \\
3 & 2.95 & 3.0 & 3.01 & 3.05 \\
4 & 13.91 & 14.15 & 14.14 & 14.11 \\
5 & 14.12 & 14.07 & 13.94 & 13.97 \\
6 & 14.22 & 14.11 & 14.07 & 14.08 \\
7 & 8.69 & 8.43 & 8.43 & 8.49 \\
8 & 8.84 & 8.7 & 8.52 & 8.49 \\
9 & 8.72 & 8.85 & 8.69 & 8.6 \\
10 & 5.79 & 5.93 & 5.48 & 5.56 \\
11 & 4.69 & 4.47 & 4.32 & 4.39 \\
12 & 3.94 & 3.44 & 3.7 & 3.63 \\
13 & 3.72 & 3.81 & 3.63 & 3.72 \\
14 & 4.43 & 4.24 & 4.25 & 4.27 \\
15 & 8.8 & 8.83 & 8.76 & 8.78 \\
16 & 2.51 & 2.52 & 2.56 & 2.5 \\
17 & 2.8 & 2.76 & 2.62 & 2.56 \\
18 & 4.63 & 4.7 & 4.59 & 4.6 \\
19 & 4.35 & 4.74 & 4.59 & 4.66 \\
20 & 3.76 & 3.83 & 3.62 & 3.63 \\
21 & 7.82 & 7.76 & 7.62 & 7.62 \\
22 & 7.65 & 7.78 & 7.56 & 7.62 \\
23 & 7.79 & 7.74 & 7.69 & 7.62 \\
24 & 7.78 & 7.5 & 7.41 & 7.44 \\
25 & 7.77 & 7.69 & 7.4 & 7.44 \\
26 & 7.77 & 7.76 & 7.56 & 7.62 \\
27 & 7.87 & 7.63 & 7.62 & 7.65 \\
28 & 5.14 & 5.31 & 5.07 & 5.15 \\
29 & 7.7 & 7.81 & 7.69 & 7.62 \\
30 & 7.74 & 7.72 & 7.57 & 7.56 \\
\hline & & & &
\end{tabular}


Table 2. Errors of building height measurement by method used (Unit: meter)

\begin{tabular}{|c|c|c|c|}
\hline Building & LP360 & ArcScene & Pictometry \\
\hline 1 & 0.33 & 0.18 & 0.01 \\
\hline 2 & 0.04 & 0.01 & -0.07 \\
\hline 3 & -0.10 & -0.05 & -0.04 \\
\hline 4 & -0.20 & 0.04 & 0.03 \\
\hline 5 & 0.15 & 0.10 & -0.03 \\
\hline 6 & 0.14 & 0.03 & -0.01 \\
\hline 7 & 0.20 & -0.06 & -0.06 \\
\hline 8 & 0.35 & 0.21 & 0.03 \\
\hline 9 & 0.12 & 0.25 & 0.09 \\
\hline 10 & 0.23 & 0.37 & -0.08 \\
\hline 11 & 0.30 & 0.08 & -0.07 \\
\hline 12 & 0.31 & -0.19 & 0.07 \\
\hline 13 & 0.00 & 0.09 & -0.09 \\
\hline 14 & 0.16 & -0.03 & -0.02 \\
\hline 15 & 0.02 & 0.05 & -0.02 \\
\hline 16 & 0.01 & 0.02 & 0.06 \\
\hline 17 & 0.24 & 0.20 & 0.06 \\
\hline 18 & 0.03 & 0.10 & -0.01 \\
\hline 19 & -0.31 & 0.08 & -0.07 \\
\hline 20 & 0.13 & 0.20 & -0.01 \\
\hline 21 & 0.20 & 0.14 & 0.00 \\
\hline 22 & 0.03 & 0.16 & -0.06 \\
\hline 23 & 0.17 & 0.12 & 0.07 \\
\hline 24 & 0.34 & 0.06 & -0.03 \\
\hline 25 & 0.33 & 0.25 & -0.04 \\
\hline 26 & 0.15 & 0.14 & -0.06 \\
\hline 27 & 0.22 & -0.02 & -0.03 \\
\hline 28 & -0.01 & 0.16 & -0.08 \\
\hline 29 & 0.08 & 0.19 & 0.07 \\
\hline 30 & 0.18 & 0.16 & 0.01 \\
\hline Average & 0.1280 & 0.1013 & -0.0127 \\
\hline SD & 0.1585 & 0.1130 & 0.0527 \\
\hline RMSE & 0.2017 & 0.1504 & 0.0534 \\
\hline
\end{tabular}

Table 3. ANOVA and Tukey test on absolute building height measurement errors by method used (Unit: meter)

\begin{tabular}{lllllll}
\hline SUMMARY & \multicolumn{1}{l}{ Count } & Sum & Average & Variance & Tukey & \\
\hline Groups & 30 & 1.38 & $\mathbf{0 . 0 4 6 0}$ & 0.000756 & $\mathbf{A}$ & \\
Pictometry & 30 & 5.08 & $\mathbf{0 . 1 6 9 3}$ & 0.012413 & $\mathbf{B}$ & \\
LP360 & 30 & 3.74 & $\mathbf{0 . 1 2 4 7}$ & 0.007315 & $\mathbf{B}$ & \\
ArcScene & & & & & & \\
ANOVA & & $d f$ & MS & $F$ & P-value & F critical \\
Source of Variation & SS & $d f$ & & & \\
Between Groups & 0.233947 & 2 & 0.116973 & 17.13092 & $\mathbf{5 . 3 3 E - 0 7}$ & 3.101296 \\
Within Groups & 0.594053 & 87 & 0.006828 & & & \\
Total & 0.828 & 89 & & & & \\
\hline
\end{tabular}

\section{Conclusions}

The use of ArcScene and LAS 360 did not differ in building height estimation and were not statistically different. However, ArcScene does have a RMSE of $1.50 \mathrm{~m}$ that is lower than that of LP360 (0.2017 m).with an average error of $0.10 \mathrm{~m}$ for ArcScene and an average error of $0.13 \mathrm{~m}$ for LP360. These errors were primarily due to the interprelation of the edge in the display error. As experience increases, the amount of error may decrease. Pictometry hyperspatial imagery was accurate to with an RMSE of $0.0534 \mathrm{~m}$ with a demonstrating a reliable and 
consistent measure of building height as found with previous height investigations (Kulhavy, Unger, Hung \& Douglass, 2015).

The independence of students completing the project with a UAS by collecting data for LP360 and ArcScene and utilizing Pictometry as an onscreen measuring tool points to the need to integrate remote sensing, statistical analysis and synthesis of data into a comprehensive project (Bullard et al., 2014). The students demonstrated that the four-step method of developing the project, implementing the project, analyzing the data and synthesizing the information is essential in hands-on experiential learning (Unger et al., 2016). Collaborative learning for high-impact practices of using UAS are essential in natural resource education (McBroom, Bullard, Kulhavy \& Unger, 2015).

This method of synthesis of information by undergraduate spatial science students applies to analysis for other projects in remote sensing and demonstrates both the use of UAS in research and teaching and the applications of ArcScene and LAS 360 in a novel way. UAS are important in service-learning to convey spatial data as an adjunct to a senior capstone course in forestry (Kulhavy \& Unger, 2016; Kulhavy et al., 2017). Partnerships for both quantitative and qualitative analysis reinforce the service-learning principles (Bringle, Clayton \& Price, 2012) leading to a more authentic hands-on experience. UAS is expanding in natural resource education and research. Both safety and effective use of the UAS are essential in using high-end technology in an outdoor environment to make a difference in natural resource education (Bullard et al., 2014; Bullard, 2015).

\section{Acknowledgements}

This work was supported by a McIntire-Stennis grant administered by the Arthur Temple College of Forestry and Agriculture, Stephen F. Austin State University, Nacogdoches, Texas, USA.

\section{References}

Bringle, R. G., \& Hatcher, J. A. (1996). Implementing service learning in higher education. Journal of Higher Education, 67(2), 221-239. https://doi.org/10.2307/2943981

Bringle, R. G., \& Hatcher, J. A. (2002). Campus-community partnerships: The terms of engagement. Journal of Social Issues, 58(3), 503-516. https://doi.org/10.1111/1540-4560.00273

Bringle, R. C., Clayton, P., \& Price, M. (2012). Partnerships in service learning and civic engagement. Partnerships: A Journal of Service-Learning and Civic Engagement, 1, 1-20. Retrieved from http://hdl.handle.net/1805/4580

Bullard, S. H. (2015). Forestry curricula for the 21st century-Maintaining rigor, communicating relevance, building relationships. Journal of Forestry, 113, 552-556. https://doi.org/10.5849/jof.15-021

Bullard, S. H., Stephens Williams, P., Coble, T., Coble, D. W., Darville, R., \& Rogers, L. (2014). Producing "society ready" foresters: A research-based process to revise the Bachelor of Science in Forestry curriculum at Stephen F. Austin State University. Journal of Forestry, 112(4) 354-360. https://doi.org/10.5849/jof.13-098

Gross, S., \& Kennelly, P. J. (2005). Virtual campus 101, a primer for creating 3D models in ArcScene. ArcUser. p. 26-29.

Hung, I., Unger, D., Kulhavy, D., \& Zhang, Y. (2019). Positional precision analysis of orthomosaics derived from drone captured aerial imagery. Drones, 3(2), 46. https://doi.org/10.3390/drones3020046

Khanna, R., Moller, M., Pfeifer, J., Liebisch, F., Walter, A., \& Siegwart, R. (2015) Beyond point clouds-3D mapping and field parameter measurements using UAVs. Proceedings of Emerging Technologies and Factory Automation 2015 IEEE 20th Conference. Luxembourg City, Luxembourg. p. 4. https://doi.org/10.1109/ETFA.2015.7301583

Kulhavy, D. L., Unger, D. R., Hung, I., \& Douglass, D. (2015). Integrating hands-on undergraduate research in an applied spatial science senior level capstone course. International Journal of Higher Education, 4(1), 52-60. https://doi.org/10.5430/ijhe.v4n1p52

Kulhavy, D. L., \& Unger, D. R. (2016). Service-learning and participation in a capstone spatial science course. Journal of Service-Learning in Higher Education, 5, 41-53.

Kulhavy, D. L., Unger, D. R., Zhang, Y., Bedford, P., \& Hung, I. (2016). Comparing remotely sensed Pictometry web based distance estimates with in situ total station and tape slope distances. International Journal of Geospatial and Environmental Research, 3(1), Article 3. https://doi.org/10.1117/1.JRS.8.083590 
Kulhavy, D., Unger, D., Hung, I., \& Zhang, Y. (2016). Comparison of AR.Drone quadricopter video and the visual CTLA method for urban tree hazard rating. Journal of Forestry, 114(5), 517-523. https://doi.org/10.5849/jof.15-005

Kulhavy, D. L., Unger, D. R., Grisham, R., Coble, D., Endsley, G., \& Gannon, M. (2017). Service learning for the Port Jefferson History and Nature Center: Senior capstone forestry course. Journal of Community Engagement \& Higher Education, 9(2), 67-79.

Kulhavy, D., Schalk, M., Viegut, R., Unger, D., Shockley, S., \& Hung, I. (2019). Using unmanned aircraft systems (UAS) to quantify mistletoe in urban environments. Urban Naturalist, 20, 1-10.

Latha, T. P., NagaSundari, K., Cherukuri, S., \& Prasad, M. V. V. S. V. (2019). Remote sensing UAV/drone technology as a tool for urban development measures in APCRDA. The International Archives of the Photogrammetry, Remote Sensing and Spatial Information Sciences, XLII-2/W13, ISPRS Geospatial Week 2019, Enschede, The Netherlands. https://doi.org/10.5194/isprs-archives-XLII-2-W13-525-2019

McBroom, M., Bullard, S., Kulhavy, D., \& Unger, D. (2015). Implementation of collaborative learning as a high-impact practice in natural resources education. International Journal of Higher Education, 4(4), 64-72. https://doi.org/10.5430/ijhe.v4n4p64

Society of American Foresters. (2016). Accreditation Handbook. SAF, Bethesda, MD. p. 27-28.

Themistocleous, K. (2014). The use of UAV platforms for remote sensing applications: Case studies on Cyprus. Proceedings of Second International Conference of Remote Sensing and Geoinformation of the Environment. Paphos, Cyprus. https://doi.org/10.1117/12.2069514

Unger, D., \& Kulhavy, D. (2016). Service-learning and participation in a capstone spatial science course. Journal of Service-Learning in Higher Education, 5(1), 13. https://doi.org/10.5430/ijhe.v5n3p104

Unger, D. R., Hung, I., \& Kulhavy, D. L. (2014). Comparing remotely sensed Pictometry® web-based height estimates with in situ clinometer and laser range finder height estimates. Journal of Applied Remote Sensing, 8(1), 083590. https://doi.org/10.1117/1.JRS.8.083590

Unger, D., Kulhavy, D., Williams, J., Creech, D., \& Hung, I. (2015). Urban tree height assessment using Pictometry hyperspatial 4-inch multispectral imagery. Journal of Forestry, 113, 7-11. https://doi.org/10.5849/jof.14-020

Unger, D. R., Kulhavy, D. L., Busch-Petersen, K., \& Hung, I. (2016). Integrating faculty led service learning training to quantify height of natural resources from a spatial science perspective. International Journal of Higher Education, 5, 104-116. https://doi.org/10.5430/ijhe.v5n3p104

Unger, D. R., Hung, I., Kulhavy, D. L., Zhang, Y., \& Busch-Petersen, K. (2018). Accuracy of unmanned aerial system (drone) height measurements. International Journal of Geospatial and Environmental Research, 5, Article 6. https://dc.uwm.edu/ijger/vol5/iss1/6

Unger, D., Hung, I., Zhang, Y., \& Kulhavy, D. (2018). Integrating drone technology with GPS data collection to enhance forestry students interactive hands-on field experiences. Higher Education Studies, 8(3), 49-62. https://doi.org/10.5539/hes.v8n3p49

Unger, D. R., Kulhavy, D. L., Hung, I., Zhang, Y., \& Stephens Williams, P. (2019). Integrating drones into a natural resource curriculum at Stephen F. Austin State University. Journal of Forestry, 117(4), 98-405. https://doi.org/10.1093/jofore/fvz031

Viegut, R., Kulhavy, D. L., Unger, D. R., Hung, I., \& Humphreys, B. (2018). Integrating unmanned aircraft systems to measure linear and areal features into undergraduate forestry education. International Journal of Higher Education, 7(4), 63-75. https://doi.org/10.5430/ijhe.v7n4p63

Warren-Gordon, K., Hudson, K., \& Scott, F. (2020). Voices of partnerships within the critical service-learning framework. Journal of Community Engagement and Higher Education, 12(2), 17-25.

WuDunn, M., Dunn, J., \& Zakhor, A. (2020). Point cloud segmentation using RGB drone imagery. IEEE International Conference on Image Processing (ICIP, Abu Dhabi, United Arab Emirates. p. 2750-2754. https://doi.org/10.1109/ICIP40778.2020.9191266

WuDunn, M., Zakhor, A., Touzani, S., \& Ganderson, J. (2020). Aerial 3D building reconstruction from RGB imagery. Proceedings volume 11398, Geospatial Informatics, 1139803. https://doi.org/10.1117/12.2558399 


\section{Copyrights}

Copyright for this article is retained by the author(s), with first publication rights granted to the journal.

This is an open-access article distributed under the terms and conditions of the Creative Commons Attribution license (http://creativecommons.org/licenses/by/4.0/). 